\title{
Tolerancia, práctica para la convivencia pacífica en los espacios públicos democráticos
}

Pedro Manuel Uribe Guzmán

Universidad Católica del Táchira, Venezuela

(c) 


\title{
Tolerancia, práctica para la convivencia pacífica en los espacios públicos democráticos*
}

\begin{abstract}
Resumen: el presente documento pretende explicar una noción de tolerancia como práctica de virtud que se desarrolla en las sociedades democráticas contemporáneas. La finalidad de esta práctica es lograr la convivencia pacífica sostenible ante la diversidad cultural. A través de un desarrollo descriptivo, analítico y deductivo, desde una perspectiva jurídico-filosófica, este documento procurará explicar que los problemas de tolerancia se pueden abordar positivamente bajo los principios jurídicos que informan un Estado democrático de corte liberal.
\end{abstract}

Palabras clave: tolerancia, liberalismo, prácticas, virtud, democracia.

\section{Toleration, a practice for peaceful coexistence in democratic public spaces}

\begin{abstract}
This paper expects to explain a notion of toleration conceived as an exercise of virtue that takes place in contemporary democratic societies. The aim of this practice is the achieving of peaceful and sustainable coexistence amongst cultural diversity. Through a descriptive, analytic and deductive explanation, and from a legal and philosophic scope, this paper tries to explain how the issues of toleration can be positively addressed under the liberal legal framework and the principles of democratic states.
\end{abstract}

Keywords: toleration, liberalism, practices, virtue, democracy.

Fecha de recepción: 07 de abril de 2017

Fecha de aceptación: 24 de junio de 2017

Forma de citar (APA): Uribe Guzmán, P. (2018). Tolerancia, práctica para la convivencia pacífica en los espacios públicos democráticos. Revista Filosofía UIS, 17(1), doi: http://dx.doi.org/10.18273/revfil.v17n1-2018005

Forma de citar (Harvard): Uribe Guzmán, P. (2018). Tolerancia, práctica para la convivencia pacífica en los espacios públicos democráticos. Revista Filosofía UIS, 17(1), 97-121.

Pedro Manuel Uribe Guzmán: venezolano. Doctor en Filosofía en un Mundo Global por la Universidad del País Vasco, España. Profesor asistente Universidad Católica del Táchira, Venezuela.

Correo electrónico: puribe@ucat.edu.ve

* Artículo de reflexión derivado de investigación. 


\section{Tolerancia, práctica para la convivencia pacífica en los espacios públicos democráticos}

\section{Introducción}

Con la intención de abundar a la reflexión filosófica sobre la tolerancia, se presentará la misma como una práctica de virtud. Esta noción es distinta de aquellas que buscan dirimir su naturaleza dentro del campo de las virtudes privadas o públicas, proporcionando un enfoque que decanta en la relevancia de la implementación de una cultura de la tolerancia en la sociedad contemporánea democrática. Para dar una estructura lógica a esta disertación, el documento se divide en tres apartados, que darán paso a las respectivas conclusiones.

En el primer apartado se aportaran las nociones preliminares que darán cuenta de la noción de tolerancia como práctica de virtud y su intrínseca relación con la democracia y los derechos fundamentales, así como la relevancia de los espacios públicos para la consolidación de una cultura de la tolerancia. En la segunda sección presentaré una serie de casos contemporáneos que se consideran problemas de tolerancia y, con argumentos propios y de otros autores, expresaré las soluciones que pueden plantearse en un Estado democrático liberal y, finalmente, esbozaré las conclusiones obtenidas del documento. Para lograr el cometido del presente artículo, la disertación se valió de la descripción conceptual, el análisis de parte de la amplia bibliografía sobre el tema, así como del método deductivo, de manera tal que las conclusiones aportadas puedan ser consideradas útiles a la temática estudiada.

\section{Nociones preliminares. "La tolerancia es una práctica de virtud que se verifica en democracia"}

La discusión sobre las virtudes se puede retrotraer a Aristóteles, quien identificó las virtudes del alma entre éticas e intelectuales. Así, una virtud ética es

[...] un modo de ser relativo a la elección, y la elección es un deseo deliberado, el razonamiento, por esta causa, debe ser verdadero, y el deseo recto si la elección ha de ser buena y lo que 'a razón' diga 'el deseo' debe perseguir (Aristóteles, 1985, p. 269). 
La tolerancia, aunque virtud democrática contemporánea, puede entenderse como una práctica al tenor de la concepción contenida en Tras la virtud de Macintyre (2013), quien explica que una práctica es cualquier actividad humana, compleja y coherente, también cooperativa, con la que se realizan los bienes que la sociedad requiere. Toda práctica pretende alcanzar unos modelos de excelencia que, en parte, definen a una sociedad. Por ende, las prácticas se relacionan con los fines que persiguen y con los beneficios que producen, de manera tal que se reproducen y extienden de forma sistémica. Si la tolerancia es una práctica que coge sentido como manifestación social, es porque se ha materializado a través de un conjunto de actos individuales que persiguen un fin, que no es otro que "la convivencia pacífica sostenible y duradera".

La tolerancia como práctica, para ser considerada como tal, debe producir beneficios internos y externos. Los primeros redundan en un resultado perceptible en el propio individuo que tolera que van desde la autoestima (Fetscher, 1990), hasta la propia percepción del tolerado respecto de lo provechoso que el clima democrático resulta a su propio desarrollo (Uribe, 2016). Por su parte, los segundos comprenden tanto la reputación de tolerantes como la convivencia pacífica ${ }^{1}$. Por estas razones, la noción de tolerancia como práctica, aunque distinta, no prescinde de las ideas que la sitúan como virtud privada o política pública, sino que asume que la práctica de la tolerancia está condicionada por el marco jurídico y político que le acompaña.

Aunque la tolerancia, strictu sensu, se considera una acción individual, la misma no puede determinarse sólo desde la perspectiva de cada persona, pues esto supondría una relativización en la categorización de lo intolerable que, desde el punto de vista de la sociedad política, sería inapropiado en tanto la sociedad requiere de parámetros objetivos que propicien reglas de juego claras para individuos con iguales derechos y deberes. Aunque Heyd (1996) afirme que el Estado no tolera, sino que gobierna y protege los derechos de los individuos, hay una idea de sociedad tolerante que se muestra de distintas maneras²: como los ciudadanos que son tolerantes; como la convivencia pública que resulta de los convencionalismos sociales; como el resultado del marco jurídico normativo de una sociedad; la tolerancia concebida como tolerancia del sistema político y sus instituciones; y, finalmente, como la tolerancia del Estado (Forst, 2013).

\footnotetext{
${ }^{1}$ A. Maclntyre (2013) expone con claridad la definición de bienes internos y bienes externos que produce una práctica. Estas ideas son, a la vez, tratadas por Uribe (2016) en dónde también se da una definición de tolerancia como una práctica de virtud.

${ }^{2}$ La separación del tipo de tolerancia que se considera una virtud individual frente a la idea colectiva y política está explicada por Murphy A. (1997) en Tolerance, toleration and the liberal tradition.
} 
Todo Estado de corte democrático y liberal asume como base la idea negativa de la libertad, por lo que los límites ésta resultan esenciales para evitar la alteración del orden público y hacer posible la convivencia. Es bajo esta premisa que se han construido las ideas de tolerancia y, aunque en el ámbito privado o íntimo, las personas no requieren tolerancia social, esta se hace necesaria en la esfera pública donde se exteriorizan las conductas y donde surge la necesidad de prohibir, de restringir o de suprimir algo. La diferencia puede suponer, desde un punto de vista moral, una afrenta o un daño, ergo, para evitarlo, se opta por la intolerancia. Por ello son necesarios algunos parámetros resultantes de consensos tomados en discusiones racionales que permitan conocer hasta qué punto está justificado tolerar.

La tolerancia es un proceso que va más allá de lo individual y se adentra en el campo de lo colectivo y lo político, supone la alteridad, ya que sin pluralidad no habría necesidad de tolerar. Como práctica, la tolerancia requiere de un fin, que no es otro que la convivencia pacífica sostenible en el tiempo, de allí que si se sustenta en una razón suprema, como la dignidad humana, podrá constituirse en una práctica colectiva, cooperativa y racional que conduzca a la posibilidad de convivir pacíficamente a pesar de la divergencia, inevitable en cualquier sociedad humana.

Si se consolida como tal, la tolerancia supondrá la capacidad de determinar el marco que permitirá la construcción de los difíciles límites que su propio carácter paradójico le exigen. Aunque difícil de hacerlo, el problema de los límites de la tolerancia halla dentro de lo epistemológico y lo político (Thiebaut, 2010), lo que hace aún más necesario que los problemas que le incumben se diriman dentro del marco democrático de las instituciones de justicia. De tal situación se colige que esa idea de tolerancia como neutra de valor, carece de sentido en la sociedad democrática contemporánea, donde la noción de tolerancia psicológica (King, 1998) atribuye a cada conflicto una serie de valoraciones que permiten solventar asuntos bajo los parámetros comparativos que propicia el sistema de justicia democrático.

\subsection{La tolerancia es una práctica que se verifica en democracia}

La tolerancia es llevada a cabo a diario en ese ir y venir que es compartir visiones, vidas o espacios. A su vez, la intolerancia se presenta cotidianamente, como una manera de condenar un cierto algo o alguien y su comportamiento. Cuando se comparten espacios públicos se produce la convivencia, que no es más que una consecuencia de la vida en sociedad. Esta convivencia es distinta en las sociedades democráticas abiertas que en las sociedades cerradas, por lo que la tolerancia como práctica se construye en las primeras en tanto la convivencia así lo permite. En la democracia, la esfera privada del individuo se mantiene privada sin influenciar a sus conciudadanos, pero cuando sus actos se desarrollan en la esfera pública, en espacios que son comunes o compartidos se producen encuentros y desencuentros respecto del ejercicio de los derechos fundamentales. 
De esta realidad surgen situaciones que traen la tolerancia a debate, pues toda sociedad democrática es susceptible a la prohibición, la restricción o la supresión de conductas que afectan las estructuras jurídicas, políticas y sociales estipuladas para la consecución de los fines comunes. Estas no son sino conductas que comprenden el ejercicio de derechos reconocidos, por parte de individuos o grupos distintos de los ya consolidados en el seno de dichas sociedades. Por ello, distinguir lo tolerable de lo intolerable es tarea ardua que requiere de mecanismos efectivos para ello y supone juicios de valor, en donde se pueden ser sopesados los derechos bajo parámetros de ponderación (Alexy, 2010) ${ }^{3}$, y así solucionar los desacuerdos respecto de su ejercicio.

Una sociedad democrática debe afrontar la resolución de este tipo de problemas, aunque resulten polémicos, no se resuelvan de la manera más satisfactoria o, aunque se yerre al hacerlo. No es extraño a la democracia que se caiga en complacencias respecto de ciertas actividades, favoreciendo a unas y perjudicando a otras, mediante la disposición de restricciones en el ejercicio de los mismos derechos. Con estas conductas se tergiversa el sentido de la tolerancia como práctica, falseando su cometido. La tolerancia concebida como ejercicio o práctica de virtud debe beneficiar a los individuos que la llevan a cabo, así como a esos que son tolerados. Por su parte, una tolerancia falsa o tergiversada, sirve sólo para mitigar la indignación del grupo que exige vindicación, o para aportar soluciones cortoplacistas sin abordar la naturaleza del conflicto planteado, arriesgando la convivencia pacífica sostenible.

De manera tal que la práctica de la tolerancia debe buscar soluciones constructivas a los conflictos de convivencia que provean resultados provechosos, tanto individuales como comunes, pues así como puede ser una virtud, en sí misma puede también ser la tolerancia un vicio (Maclntyre, 2006). La falsa tolerancia toma la forma de actos de poder que encubren la intención de dominación sobre determinados grupos culturales, a través de medidas que aunque con animus de integrarlos, a mediano plazo los excluyen, ya sea legitimando su condición de débiles frente a los factores de poder o indicándoles un deber de sumisión frente a la posición prevaleciente (Forst, 2013).

Cuando se favorece este modelo, se propicia la tolerancia de un individuo que "carece, para empezar, de convicciones propias en grado bastante como para enfrentarlas a cualesquiera otras, y entonces aquella tolerancia se confunde con la indiferencia o el escepticismo" (Arteta, 1998, pp. 52-53). La práctica de la tolerancia no supone ser indiferente, aunque se pueda pretender tolerar amparado por la indiferencia. La falsa tolerancia institucionaliza un discurso que normaliza la identidad inexistente entre tolerancia e indiferencia, cuando practicar la primera no

\footnotetext{
${ }^{3}$ Sobre este asunto, refiero el artículo que realicé (Uribe, 2016b) sobre la ponderación de derechos fundamentales para resolver problemas de tolerancia.
} 
es tarea ni sencilla ni neutra, como muy bien lo apunta Giner (1998). Este tipo de actitud es identificada por Arteta como una que proviene de un individuo a quien:

[...] le faltan buenas o suficientes razones para tolerar, y en tal caso aquella actitud procede de una ignorancia más o menos culpable. $\mathrm{O}$, en fin, arraiga la flaqueza de su voluntad y de su compromiso con el otro o con su sociedad, por donde su transigencia aparente obedece más bien a una real dejadez, pereza o cobardía (1998, p. 53).

El centro del debate sobre la forma en que se practica la tolerancia en las democracias de corte liberal ${ }^{4}$, donde la diversidad cultural invita a una revisión de la aplicación de los principios fundamentales que orientan el ejercicio de los derechos y la disposición de las políticas que permiten la práctica bajo examen. Así, por ejemplo, en el Estado-Nación:

[...] un único grupo dominante organiza la vida en común de manera tal que refleja su propia historia y cultura y, si las cosas marchan como se pretende, lleva hacia adelante la historia y mantiene la cultura. Son esas intenciones las que determinan el carácter de la educación pública, los símbolos y el ceremonial de la vida pública, el calendario estatal y las fiestas o vacaciones que se disfrutan (Walzer, 1998, p. 39).

En este tipo de Estado se verifica la reproducción de una determinada identidad, para favorecer a los grupos que lo han construido, mediante la creación de una estructura jurídica y política que se propaga en consecuencia. En ellos, la tolerancia se muestra como un reflejo del comportamiento de la mayoría consolidada respecto de las minorías con las que conviven dentro de sus fronteras, razón por la cual se examinan los mecanismos que regulan su integración y participación. Aunque Walzer (1998) diga que esta es una característica del Estado Nacional, considero que tales medios no le son exclusivos ya que pueden hallarse en casi toda forma de Estado. Por ello, es recomendable hablar de la práctica de la tolerancia en las democracias de corte liberal, que no son extrañas a la propagación de una identidad común.

Tal como se desprende de los argumentos de McKinnon (2006), existe una complacencia en las comunidades democráticas sobre los principios que deben regir la práctica de la tolerancia y que se dirigen a justificar los ataques de quienes se asumen buenos respecto de los malos, excusándose en la protección de la

\footnotetext{
${ }^{4}$ La tolerancia puede ser descrita también en las relaciones internacionales entre Estados, aquí no serán analizadas estas formas, pero para profundizar sobre ellas se puede revisar la obra de Walzer (1998) quien, entre otras cosas, afirma que "[...] la comunidad internacional no es anárquica; es un régimen muy débil, pero es como un régimen tolerante a pesar de la intolerancia de algunos de los Estados que la conforman. La sociedad de los Estados tolera a todos los grupos que alcanzan esa categoría de Estado y todas las prácticas que estos permiten" (p. 34). También pueden revisarse las consideraciones de Rawls (2001) sobre la tolerancia y el derecho de gentes y la posición crítica de Marcuse (1965).
} 
democracia, la libertad o el estilo de vida mayoritario, situación que para esta autora, es una amenaza mayor que cualquiera sufrida a mitad del siglo XX. La protección de estas identidades nacionales puede prestarse para la vulneración de los derechos fundamentales, piedra angular de la problemática de la tolerancia dentro de las democracias liberales.

La convivencia pacífica sostenible entre múltiples visiones discordantes, demanda la búsqueda de equilibrios en el ejercicio de los derechos de cada una de estas posturas, mayoritarias o minoritarias. De allí que bajo la igualdad de la ley se permita el ejercicio de los mismos derechos y los mismos deberes para todas aquellas personas que confluyen en una comunidad política diversa y democrática. Partiendo de allí, la implementación de una cultura donde se practique la tolerancia puede prevenir que la imposibilidad de convivir se haga patente o, peor aún, que sea fomentada por políticas de Estado.

La democracia propugna libertad, autonomía, igualdad ante la ley y, en conjunto, una idea de dignidad humana sustentada en el respeto del otro y la reciprocidad en dicho respeto. Pero también exige responsabilidad en la acción política humana y el compromiso en la defensa de estos principios, porque tal y como expresa Popper:

No debemos escoger la libertad política porque nos prometa una vida más cómoda, sino porque ella misma representa un último valor que no se puede reducir a valores materiales. Debemos escogerla como lo hizo una vez Demócrito, quien dijo: "Prefiero la vida pobre en una democracia a una riqueza bajo una tiranía", y "La pobreza de una democracia es mejor que toda la riqueza bajo una aristocracia, pues la libertad es mejor que la servidumbre" (1995, p. 146).

Ante el fenómeno globalizador —descrito por Chumakov (2010) como un proceso tan objetivo como la salida del sol—, se hacen evidentes los problemas estructurales de la democracia para materializar sus principios fundamentales, tales como la autonomía y la igualdad ante la ley, mostrándose proclive a los errores y a las contradicciones. La diversidad cultural hace que grupos minoritarios y mayoritarios reclamen primacía en el ejercicio de sus derechos, haciendo insalvables las tensiones cotidianas, que se manifiestan de manera especial en esos espacios que son considerados públicos. De ello que no siempre la convivencia democrática sea afable ni que las soluciones implementadas sean positivas.

Todo proyecto nacional aspira a su consolidación, "por regla general las democracias liberales han aspirado a forjar una identidad nacional común entre la gente que reside de manera permanente en su territorio. Además, su proyecto de "construcción nacional" ha sido sorprendentemente efectivo" (Kymlicka, 2006, p. 47). Esta reproducción se ejecuta desde la instauración de un idioma oficial 
(situación que no es extraña en las constituciones contemporáneas ${ }^{5}$ ), o mediante la presencia de una institucionalidad oficial, uniformidad de las celebraciones nacionales y los días de fiesta laboral; además de símbolos y otros elementos que procuran cohesión entre los habitantes de un territorio determinado, generando la existencia de una identidad que se va fortaleciendo con el tiempo.

Los Estados Unidos de América es una referencia constante en Kymlicka ${ }^{6}$ como una nación que influenciada por los movimientos migratorios, ha logrado una construcción nacional con elementos comunes como el idioma:

¿Quién habría imaginado que inmigrantes de todo el mundo llegados a las costas americanas sin conocimiento del idioma inglés o de las instituciones norteamericanas, habrían adoptado tan rápidamente una identidad nacional americana y aceptado el principio de que sus oportunidades se relacionarían muy estrechamente con su participación en instituciones nacionales comunes que operan en inglés? (Kymlicka, 2006, pp. 47-48).

Esta idea está presente también en Walzer (1998), quien le afirma como el modelo de tolerancia de la sociedad de inmigrantes, formada por grupos que han dejado sus propios Estados nacionales para adherirse a otro que les acoge y permite mantener sus costumbres e identidad. Allí, se toleran "las elecciones y acciones individuales: los actos de adhesión, la participación en rituales internos y religiosos, la proclamación de diferencias culturales, etc." (Walzer, 1998, p. 46). La sociedad venezolana también puede señalarse dentro de las sociedades de inmigrantes, cuyo proceso inició con el boom petrolero de comienzos del siglo XX, aunque la democracia de corte liberal no se instauró sino hasta después de 1958. Sin embargo,

[...]Ya en 1920, comienzan a realizarse las primeras actividades exploración y explotación petroleras, lo que generó un cambio en el comportamiento demográfico de la población, tanto interna como externa. Por este motivo se establecen las primeras compañías extranjeras que impulsaron la inmigración desde el exterior (Álvarez, 2007, p. 90).

Las necesidades de mano de obra tecnificada y la poca densidad poblacional ${ }^{7}$, hicieron necesaria una política migratoria de puertas abiertas, puesta en marcha durante el gobierno de López Contreras, dando prelación a la migración europea (española, portuguesa e italiana). Conforme narra Troconis:

\footnotetext{
${ }^{5}$ Por mencionar algunos ejemplos contemporáneos, la Constitución venezolana dispone el idioma castellano como oficial en su artículo 9; la Constitución colombiana en el artículo 10; y, la Constitución española hace lo propio en el artículo 3, aunque refiere otras lenguas como co-oficiales.

${ }^{6}$ Para ahondar en este tema pueden consultarse las obras Ciudadanía multicultural (Kymlicka, 1996) y Estados, naciones y culturas (Kymlicka, 2004).

Entre 1920 y 1937 (año de la primera Ley de Extranjeros), la población total venezolana osciló de entre 2.992 .468 y 3.565 .014 habitantes, conforme datos aportados por la Universidad de Los Andes (s/a) a través del Instituto de Investigaciones Económicas y Sociales.
} 
En el programa de gobierno presentado por el General López Contreras asume una posición muy clara sobre la inmigración; dice que entre las necesidades del país está la de una población relativamente densa, físicamente fuerte, moral e intelectualmente educada y que disfrute de una economía próspera. Para lograr esto es necesario promover la inmigración y para lograr una verdadera asimilación al medio es indispensable que el país goce de libertad [...] (1986, p. 232).

Esta política fue luego restringida por el presidente Medina Angarita y reinstaurada, con aún mayor flexibilidad, por el dictador Marcos Pérez Jiménez, pues como afirma Álvarez: "A partir de 1952 se dio un impulso hasta entonces desconocido de la inmigración en Venezuela, lo que permitió una inmigración espontánea de una gran cantidad de personas sin verdadero criterio de selección" (2007, p. 90). Ya en la etapa democrática, se distingue una inmigración proveniente de países suramericanos, especialmente colombiana, chilena, argentina y uruguaya (Álvarez, 2007). De esto se colige que los procesos migratorios y su consecuente diversidad cultural no son exclusivos de una democracia liberal — como Estados Unidos-, sino de Estados como Venezuela, democratizado después de 1958 con una clara influencia de estos movimientos.

Tanto en las sociedades de inmigrantes, como los Estados nacionales y multinacionales, se instauran políticas para la propagación de una cierta identidad nacional: ser venezolano, francés o español, respectivamente. La asunción de estas políticas o elementos de cohesión, determinará la relación de las minorías nacionales, religiosas o de inmigrantes. Esto puede ser positivo cuando se trata de procesos migratorios como los ocurridos en Venezuela o en los Estados Unidos en dónde se han incorporado festividades o tradiciones que no alteran esa identidad nacional. Así, el día de San Patricio se ha convertido en una festividad común dentro de la sociedad norteamericana, como la presencia de barrios chinos como parte del panorama urbano de las grandes ciudades; y, para 2013 Venezuela era el tercer país en consumo per cápita de pasta (International Pasta Organisation, 2014).

Estos modelos no son comparables a la complejidad y dificultad que supone la integración de minorías nacionales que han sido absorbidas por otros Estados como consecuencia de procesos históricos, como las poblaciones originarias en el continente americano ${ }^{8}$, o las naciones vasca y catalana en España; los flamencos en Bélgica, los quebequenses en Canadá. Tampoco presenta respuestas a la migración musulmana consecuencia de la inestabilidad en Oriente Medio, ni respecto de otros grupos religiosos, nacionales, políticos o minorías sexuales.

\footnotetext{
${ }^{8}$ Es menester indicar que aquí no incluyo a las mayorías nacionales de países como Bolivia donde más del $60 \%$ de la población es indígena originaria, o Guatemala donde casi el $40 \%$ de la población total es indígena (Comisión Económica para América Latina y el Caribe, 2010).
} 
No es correcto hablar de homogeneidad en la sociedad democrática contemporánea, así como tampoco es sencillo determinar la legitimidad mayoritaria para imponerse a través de los mecanismos democráticos sobre cualquier grupo minoritario, menos aún a través de la discriminación y la segregación. Ya para el siglo XIX, Mill (1970) avizoraba que la sociedad debería estar siempre en guardia contra la tiranía de las mayorías, idea que hoy cobra relevancia cuando se pretende reducir el sistema de gobierno democrático a un electoralismo de corte mayoritario. No debemos nunca olvidar la paradoja democrática9, que abre la posibilidad de prescindir de ella mediante sus propios mecanismos.

La convivencia en las sociedades democráticas ha cambiado, los espacios públicos son distintos, la vida diaria se lleva a cabo en diferentes ágoras. Recordemos que los griegos tuvieron en el ágora un elemento fundamental para la participación política, la difusión de ideas, el teatro, la política, los juegos y el comercio. Por su parte, los romanos tenían el Foro lugar central de la ciudad donde convergía el comercio, la política y la religión. Hoy, los centros de encuentro son los parques, las plazas, los bulevares, las ferias, las playas, entre muchos otros como las redes sociales, plazas digitales donde convergen con inmediatez diversidad de asuntos. Aunque en las sociedades no democráticas la convivencia también fluye en los espacios públicos, es en democracia donde la divergencia abre el camino a la práctica de la tolerancia.

Todo miembro de una comunidad democrática tiene el deber de propiciar la responsabilidad en la convivencia dentro de los espacios públicos. Estos son algo más que el lugar visible del paisaje urbano o rural, son el lugar en donde se forjan las relaciones de los individuos, se ejercen los derechos, se cumplen los deberes ciudadanos y se da forma a la democracia. Sin embargo, la convivencia está condicionada por la desigualdad estructural que generan los marcos jurídicos y las instituciones, que reflejan los valores y las expectativas de los grupos dominantes que guardan una relación estrecha con la formación de ese Estado y que conviven con otros grupos menos arraigados, a los que les resulta más difícil y costoso desarrollarse, a diferencia de los primeros (McKinnon, 2006).

En efecto, en las sociedades democráticas contemporáneas se plantean lo que Kymlicka denomina «cultura societal» "formada en derredor de una lengua e instituciones sociales comunes y no alrededor de creencias religiosas, tradiciones familiares o estilos de vida personales" (2004, p. 52). Esto tiene sentido si se percibe desde la laicidad del Estado, así como del imperativo de neutralidad que, como ficción, orienta la acción política pública y reduce los riesgos de que el Estado tome partido respecto de ésta o aquella idea. Por ende, la «cultura societal» se construye a través del idioma y las instituciones sociales comunes y no es ajena a ningún Estado.

\footnotetext{
9 Popper la define como "la posibilidad de que la mayoría decida que gobierne un tirano" (2006, p. 585).
} 
Es cierto que la consecución del bien común es uno de los fines del derecho democrático, pero también lo es que los fines de los miembros de las mayorías nacionales son distintos que los de otros grupos. Esto se debe a que tanto las mayorías nacionales como las minorías, favorecen la reproducción de su propia cultura para proporcionar a sus miembros confort y una escala de valores con las que puedan desarrollar su propia individualidad. Kymlicka en Estados, Naciones y Culturas (2004), considera normales las semejanzas del comportamiento entre mayorías y minorías, para proteger sus propias identidades. De manera tal que la práctica de la tolerancia depende de todos estos elementos, que van desde la propia estructura democrática, sus falencias y fortalezas, la instauración de culturas societales, las tensiones entre grupos diferentes y la defensa de sus propios intereses.

Estas situaciones son propias de la imperfectibilidad democrática, que se reproducen en los espacios públicos compartidos, reflejando la propia diversidad cultural humana, campo de cultivo propicio para la propagación de la práctica de la tolerancia. Sin el conflicto que surge de la divergencia, de la necesidad de prohibir, suprimir o restringir aquello que no se comparte, la tolerancia sería innecesaria; pero este no es el caso, pues a través de la tolerancia puede preservarse la diversidad cultural. Por eso, en la democracia contemporánea de corte liberal, los espacios públicos son lugares de interacción y de encuentro, pero también de distensión.

\subsection{La tolerancia es una práctica ligada a los derechos humanos fundamentales}

El amplio rango de derechos reconocidos por los Estados democráticos tiene su baremo en la Declaración Universal de los Derechos Humanos (Asamblea General de las Naciones Unidas, 1948), de donde han surgido distintas normas para la salvaguarda de derechos individuales y culturales. Es que tal como afirma Scanlon (2003), los derechos humanos son aplicables no solamente a los países que como los nuestros los han reconocido en su marco institucional, sino que aplican, virtualmente, a todos los países. Bajo el imperio de la ley, todos somos iguales, esto es, humanos con los mismos derechos y deberes. Este principio fundamental no es más que una garantía otorgada a cada uno de los miembros de la comunidad política de que ante cualquier obligación impuesta a un individuo por cualquier vía legítima y democrática, se generará de forma automática una garantía de que, bajo las mismas circunstancias, la misma obligación le será impuesta a cualquier otro.

Una democracia sustentada en este principio no es más que un sistema construido bajo la idea de que todos y cada uno de los individuos deberían poder acceder a los mismos beneficios que otorga este sistema de gobierno. Esto se complementa con la idea de libertad en negativo, que supone la imposibilidad de 
interferir en el ejercicio de los derechos del otro. Como bien lo explica Mill: "Las reglas morales que prohíben que unos causen daño a otros (entre las cuales nunca debemos olvidar incluir la interferencia perjudicial en las libertades mutuas) son más vitales para el bienestar humano que ninguna otra actividad" (1984, p. 131).

La irreductible diferencia que hace a cada ser humano único, pero igual al otro en su propia e irreductible diferencia, es descrita por Arendt así: "La pluralidad es condición de la acción humana debido a que todos somos lo mismo, es decir, humanos, y por tanto nadie es igual a cualquier otro que haya vivido, viva o vivirá" (2009, p. 22). Es esta condición la que debe ser recogida por cualquier marco jurídico institucional para que aunque no exista aceptación, se pueda propiciar la diferencia. Un Estado debería garantizar unas ciertas condiciones, y en el caso de uno de corte liberal debo argüir, junto con Kymlicka, que:

[...] el respeto al valor moral de las personas requiere que el Estado no solamente cumpla estas obligaciones negativas [integridad física, libertad de religión, libertad de asociación], sino que también proporcione diversas formas de asistencia positiva (por ejemplo, servicios públicos de salud, educación, asistencia social). El respeto al valor moral de los individuos también implica el derecho de resistencia y de derrocar a la autoridad política que niegue a la gente estas libertades y servicios básicos (2006, p. 36).

Bajo estos parámetros, se puede comprender que la tolerancia como práctica se desarrolle en una sociedad abierta, donde se muestra relevante y útil para la convivencia. Es en las sociedades abiertas donde se abordan los problemas derivados de la diversidad cultural, porque hacerlo es un mandato que surge del mismo respeto de los Derechos Humanos fundamentales. En una sociedad abierta, la diversidad es una excusa para la integración y no el sustento de la segregación, la discriminación y la exclusión. De esta manera, los motivos de toda acción humana política ${ }^{10}$ tienen una relación directa con los verdaderos objetivos que persigue, inspirados en ese espíritu colectivo que Arendt (2007), tomando una idea de Montesquieu contenida en El espíritu de las leyes, denomina el "espíritu de la acción", y que no es más que la convicción fundamental que un grupo comparte y que le inspira.

En una democracia, la libertad, la igualdad, la justicia y la paz son principios de acción que orientan la acción política y que encuentran en la práctica de la tolerancia uno de sus muchos instrumentos. La tolerancia es una práctica de virtud que se lleva a cabo cuando la contraposición de posiciones disímiles a través de la discusión racional orientada por la protección de los derechos humanos fundamentales, permite obtener beneficios individuales y colectivos. Pero también será la intolerancia un ejercicio de virtud Maclntyre (2006), en tanto y cuanto

\footnotetext{
${ }^{10}$ Aquí, al hablar de acción humana me refiero a la dimensión de la condición humana descrita por H. Arendt (2009) y que junto con el trabajo y la labor, la conforman.
} 
permita lograr los mismos provechos. La práctica de la tolerancia supone un compromiso profundo con los beneficios que promueve, pues el tolerar conlleva no sólo un proceso individual en el que una persona reconoce a otra, sino que también supone una visión colectiva marcada por la necesidad de coexistencia.

Para que esta práctica coja sentido, se debe extender como un cúmulo de acciones individuales convencidas de su utilidad. Tal como lo afirma Fetscher, la tolerancia supone "la limitación de las propias exigencias y de los propios intereses. Es lo que comúnmente se designa como 'consideración'. La tolerancia exige un acercamiento al otro, su reconocimiento y el respeto de su dignidad" (1990, p. 151). En consonancia con argumentos anteriores, afirmo que los beneficios internos se producen para quien tolera y para quien es tolerado, quien la recibe como una muestra de respeto y consideración para con su propia dignidad. Él, no se verá como un factor de disrupción y contribuirá a propagar los beneficios que la democracia le proporciona al permitirle su desarrollo. Pero, si se cae en el ámbito de la imposición, entonces estaremos propiciando una sociedad incapaz de sostener los beneficios que predica.

\section{Algunos problemas de tolerancia contemporáneos}

En los párrafos que anteceden se ha tratado de exponer una visión de tolerancia como una práctica o ejercicio de virtud que es sólo posible de materializar en la democracia contemporánea de corte liberal, centrada en la noción de derechos humanos fundamentales. Esta idea no escapa de la disyuntiva que plantea Kymlicka sobre el fundamento sobre el que se construye la democracia contemporánea: la autonomía o la tolerancia. Centrarse en la autonomía puede decantar en el error de alienar y socavar a los grupos iliberales, mientras que hacerlo en la tolerancia tendería a favorecer exclusivamente los derechos de la minoría. Esto no obsta a poner ambos principios en una balanza, pues "lo que distingue a la tolerancia liberal es precisamente su compromiso con la autonomía; es decir, la idea de que los individuos deberían tener libertad para valorar y, potencialmente, revisar sus fines actuales" (Kymlicka, 1996, p. 218).

Establecido esto, es menester hacer referencia a ciertos casos contemporáneos en los que la tolerancia ha supuesto inconvenientes para las sociedades democráticas, y que han sido abordadas desde una perspectiva institucional, esencial para la conformación de una cultura de la tolerancia. En primer lugar haré referencia al uso del velo y las mujeres islámicas en los países con democracias liberales. Este asunto ha copado las discusiones por décadas, especialmente en Europa, dónde se han establecido límites a su uso. En el caso de Francia, el asunto puede estudiarse desde el año 1989 (Laborde, 2003) con la expulsión de tres niñas de un colegio por usar el velo islámico, caso que abrió un amplio debate sobre el laicismo ${ }^{11}$.

\footnotetext{
${ }^{11}$ En el mismo documento de Laborde (2003) se hace un examen exhaustivo del asunto del velo islámico en Francia y el laicismo.
} 
En el año 2004 se prohibió en Francia (Ley 2004-228, 2004) la disposición de símbolos religiosos en las escuelas públicas (cristianos, judíos o musulmanes), levantando un debate interesante sobre los límites de la libertad religiosa y su relación directa con la laicidad del Estado De esta manera, la disposición de crucifijos en una escuela pública, resultaría tan ofensiva como el uso del hiyab en sus aulas, esto ya sin mencionar el uso de otras prendas relativas al islam como el burka o el niqab. Esta discusión no está cerrada, y la polémica se reavivó cuando en Cannes se emitió una ordenanza prohibiendo el uso del burkini después de su aparición en una playa local.

Para el burgomaestre de Cannes, David Lisnar (citado por BBC Mundo, 2016): "la ropa de playa que muestre de manera ostentosa la afiliación religiosa, cuando Francia y lugares de devoción están siendo blanco de ataques terroristas, conduce a crear riesgos de perturbar el orden público". La decisión fue dictada durante el estado de emergencia (Decreto $\left.N^{\circ} 2015-1475,2015\right)$ declarado con posteridad a los ataques de París, por lo que el contexto es determinante para entender lo ocurrido. Por su parte, el director general del ayuntamiento, Thierry Mingoule (citado por El Mundo, 2016), afirmó que el uso del burkini "es una 'señal de adhesión al yihadismo' y plantea además 'problemas de higiene'”.

Al considerar que usar el burkini es una demostración llamativa de extremismo islámico, se hace un juicio de valor absoluto sobre una prenda de vestir que tiene una connotación de identidad con la confesión religiosa de una minoría y no se pueden comparar las prohibiciones relativas a la disposición de elementos religiosos en un establecimiento público adscrito al Estado, con normar códigos de vestimenta en los espacios públicos. En este caso, los principios de autonomía de la voluntad y libertad religiosa deben tener primacía frente a la laicidad del Estado que, como bien lo explica McKinnon (2006), puede ser expresada, primero, como autonomía individual, de forma tal que leyes y políticas estén orientadas a fomentar en los individuos el ejercicio de sus profesiones de fe sin sentirse dominados e influenciados por los grupos no democráticos de la sociedad; y en segunda instancia, puede la laicidad ser entendida como lealtad civil y ciudadanía activa, asociada con el republicanismo. Lo contrario, supondría que el Estado puede inmiscuirse en las decisiones personales de los ciudadanos, ante situaciones que no afectan el ejercicio de los derechos de otros, sino que simplemente consiste en ejercitar los propios.

Aunque esta ordenanza fue revocada por el Counseil D'Etat francés (2016), su implementación tuvo consecuencias, especialmente la disyuntiva que supone la interpretación de los principios que orientan la democracia, especialmente referidos al ejercicio de los derechos por parte de una minoría, cuando ante el ojo público suscitan controversia. En las democracias liberales no se prohíbe a una monja tomar un baño en la playa mientras usa su hábito y, en Francia, el bañarse en toples es común entre las mujeres, aunque resulte ofensivo para las minorías 
musulmanas o para algunas sectas cristianas. La prohibición de Cannes puede considerarse como un acto de intolerancia con el que se pretendió transformar el laicismo en una cuestión de policía moral, incompatible con los principios fundamentales de libertad religiosa y autonomía de la voluntad, creando una situación similar a la que puede ocurrir en un Estado no liberal y que afectó la convivencia y el sentido de los espacios públicos compartidos.

No existe el derecho de imponer los derechos liberales en las sociedades democráticas contemporáneas. Incluso, McKinnon (2006) disertando sobre el tema del velo, afirma que creer que su uso es siempre una medida de coerción respecto de la mujer o una señal de hegemonía patriarcal, es una suposición que niega la posibilidad de que se trate realmente de una muestra genuina de fe, y respecto de los códigos de vestimenta se pregunta:

What basic right does wearing a hijab violates? If rights protect important interests, then the claim that womens' basic rights are violated when they wear the hijab as a part of an Islamic dress code depends on establishing that all people have an important interest in being free from dress codes. But there is no such important interest, and hence no such right (McKinnon, 2006, p. 115).

Puede ser que esta razón explique la postura de Forst (2013) sobre las lecciones del discurso de tolerancia que apela a la consciencia sobre aquello en los fundamos nuestra critica una praxis, si a la defensa de un derecho universal o de una forma particular de vida, como usar pantalones vaqueros o cualquier otra prenda de vestir. En este sentido, Kymlicka (1996) enseña que promover y defender los derechos liberales no es arrogarse el derecho de imponer el liberalismo a los grupos que no lo comparten. La imposición dificulta la convivencia y la integración.

En el caso de la tolerancia religiosa, McKinnon (2006) acierta al afirmar que una de las ventajas de privatizar las creencias religiosas es asegurar los espacios para que cada confesión pueda realizar sus prácticas. Dejar discurrir los asuntos de la salvación de las almas desde un punto de vista estrictamente privado es uno de los grandes pilares del Estado democrático de corte liberal. De manera tal que prohibiciones como la del burkini se aleja del imperativo de neutralidad del Estado que toma posición sobre actos individuales que no son más que ejercicio de derechos individuales reconocidos por el ordo democrático. Distinto sería que el Estado garantizase la protección de la mujer musulmana que decidiese no usar la indumentaria religiosa por considerarlo hegemónico y vulnerador de sus derechos fundamentales como mujer. Pero este no es el caso y los espacios públicos, como la playa en donde una mujer decide usar un burkini, está dispuesta para el ejercicio de los derechos fundamentales, siempre que no vulnere el de otros. 
El tema del velo islámico en Gran Bretaña es estudiado por Innerarity (2013), quien lo diferencia del caso francés y alemán (no traído a colación aquí). Para ella:

[...] el liberalismo británico explica que el estado haya ocupado un lugar marginal en las controversias sobre el velo islámico. Esta falta de protagonismo se manifiesta, en primer lugar, en el hecho de que no hay en el debate una referencia a un proyecto colectivo, más allá de la protección de los derechos individuales, $y$, en segundo lugar, en que no se haya recurrido a la neutralidad del estado como un argumento en la controversia, cosa que sí ha ocurrido en los otros dos países (Innerarity, 2013, pp. 154-155).

Con esto, se establece que el tratamiento dado a este caso específico tiene mucho que ver con los valores que se vindican en cada país, puesto que al dar primacía a un derecho respecto de otro se verifica la adopción de medidas disímiles respecto de determinadas prácticas culturales. Así, en el Reino Unido, los Sijs que laboran en el área de la construcción están exentos de usar casco protector (Department for Work and Pensions, 2015), y, recientemente, el Departamento de Policía de la ciudad de Nueva York (2016), decidió que permitirá “a los agentes de la comunidad sij (religión monoteísta que combina elementos del hinduismo y del islamismo) vestir su tradicional turbante y dejar crecer su barba, como indican los preceptos de su religión" (Univisión, 2016).

Ahora, volcando el estudio al campo de prácticas culturales no religiosas, tenemos a la mutilación genital femenina. Sobre ella, la Organización Mundial de la Salud (2012) dice que es "una violación de los derechos humanos de las mujeres y niñas. Refleja una desigualdad entre los sexos muy arraigada, y constituye una forma extrema de discriminación de la mujer." Por su parte, Heyd (1996) cree que aunque estemos seguros de que es moralmente inaceptable, porque no tenemos razones para aceptarla o aprobarla, debemos al menos tolerar a los individuos o comunidades que la practican porque somos capaces de entender, o respetar, que esa práctica es central para esa cultura.

Sobre la misma, McKinnon (2006) apela al principio liberal volenti non fit iniuria, como una forma de sopesar las formas en que esta costumbre se lleva a cabo dentro de las sociedades liberales, especialmente porque restringirla fomentaría su realización al margen de la ley, incrementando los riesgos que la misma, en sus múltiples variables, conlleva para las mujeres. Pero, si bajo las reglas de la capacidad jurídica, una mujer plenamente capaz y perteneciente a la «comunidad de sentido» ${ }^{12}$ la considera central para su desarrollo, no debería ver

\footnotetext{
${ }^{12}$ McKinnon (2006) utiliza la frase «community of meaning» que aquí se traduce libremente como comunidad de sentido. Para la autora, tal comunidad es aquella en donde la pertenencia al grupo y sus prácticas son relevantes para la realización de los objetivos individuales y grupales, sin estos no se puede conseguir porque no pueden ser alcanzados de otra forma.
} 
limitado su derecho a hacerlo como si se tratase de un incapaz. La complejidad de este asunto lo hace más polémico que hablar del velo o del turbante, e involucra no sólo a la autonomía individual, sino las protecciones a la integridad física y las visiones sobre el daño.

El tratamiento dado a esta práctica es diverso según el país que lo haga. Conforme explica McKinnon (2006), en Estados Unidos se prohíbe a toda mujer menor de 18 años, mientras que en Canadá, el Reino Unido y Australia ${ }^{13}$ está totalmente prohibida. El otorgamiento del consentimiento es un punto de inflexión para la realización de determinadas actividades que pueden implicar, una afrenta a la integridad física, tal es el caso de las prácticas sexuales sadomasoquistas o, inclusive, tatuarse o la mutilación corporal. Incluso, la circuncisión, judía o islámica, podría entrar dentro de la protección de la infancia, así como de la protección contra el daño físico.

En el caso de la circuncisión masculina, que se enmarca dentro de las prácticas religiosas, la Corte del Distrito de Colonia, Alemania, en fecha 7 de mayo de 2012 (citada por Durham University, 2012), consideró que practicarla en un niño musulmán de cuatro años era una ofensa ilegal por causar daño corporal al niño, afectando su derecho a la integridad física. Sin embargo, la Corte se abstuvo de condenar al practicante de la misma. Esta situación, y el revuelo ocasionado al respecto, hicieron necesaria una reforma del Código Civil alemán ${ }^{14}$, incluyendo el §1631d en donde la circuncisión del hijo varón se dispone como atributo decisivo derivado de la patria potestad, así como la posibilidad de su práctica por funcionarios de talante religioso.

Sobre esto, Yurdakul (2016) considera que la percepción sobre el ritual de la circuncisión masculina no es un problema exclusivo de la sociedad alemana, sino que se trata de quién tiene el derecho de decidir sobre el propio cuerpo en las sociedades occidentales, donde judíos y musulmanes siguen siendo considerados extranjeros, y sus prácticas expuestas a la estigmatización como amenaza pública. El mismo Yurdakul (2016) afirma que tanto la inclusión como la exclusión social son decididas en las cortes locales, los debates en los medios de comunicación y en las declaraciones de los académicos. Este tipo de observaciones no son sino consecuencia de la reproducción de la identidad nacional mayoritaria y la reticencia a utilizar los propios principios democráticos para favorecer la integración de las culturas minoritarias.

13 La Australian Medical Association (2017) estima que un 10\% de pediatras han tratado
pacientes que han sufrido mutilación genital femenina; asimismo, afirma que en el
Royal Hospital de Melbourne se atienden entre 600 a 700 mujeres con complicaciones
relacionadas a esta praxis.
${ }^{14}$ Para consulta del texto íntegro, véase Bundesministerium der Justiz für Verbraucherschutz (2015). Revista Filosofía UIS, vol. 17, $n .^{\circ} 1$, enero-junio de 2018 
Podemos también encontrar situaciones que traen a colación factores culturales, religiosos y trato ético respecto de los animales, como ocurre en Venezuela donde recientemente se admitió una solicitud de nulidad en contra de la Ordenanza modificatoria sobre tenencia, control, registro, comercialización y protección a la fauna (2006). En esta solicitud, la minoría religiosa Yoruba requiere la nulidad esta norma, porque al prohibir los sacrificios animales, impide la expresión de su propia religión en el territorio de Caracas. Dicha solicitud fue admitida por la Sala Constitucional del Tribunal Supremo de Justicia venezolano (2016), trayendo a colación la posición venezolana respecto de la libertad religiosa ${ }^{15}$ y el trato ético respecto de los animales en una sociedad donde aproximadamente el $71 \%$ de la población es católica (Aguirre, 2012) y las peleas de gallo, las corridas de toros y el coleo, son actividades tradicionales que se llevan a cabo en distinto lugares de ese país. Este caso es una solicitud para el ejercicio de derechos fundamentales de parte de una minoría religiosa que seguramente maracará un antes y después en materia de libertad de cultos.

Para finalizar el examen de casos de tolerancia referiré la decisión Obergefell y otros v. Hodges (2015), donde dispuso la posibilidad del matrimonio entre parejas del mismo sexo en todo el territorio de los Estados Unidos de América. Esta decisión esboza una serie de criterios que dejan claro que su contenido no constituye una afrenta a ninguna religión, ideología o posición filosófica, sino un ejercicio de responsabilidad desde la neutralidad del Estado, una valoración evolutiva de la institución del matrimonio civil y un reconocimiento a los derechos constitucionales. A pesar de ello, la resistencia a ella no se hizo esperar, como se desprende de los actos de Kim Davies, quien en Kentucky se negó a casar a una pareja del mismo sexo y afrontó pena de prisión por ello (El Mundo, 2015), anteponiendo su creencia religiosa a su rol de funcionario. Distinto hubiese sido que Davies alegase la objeción de conciencia para ella celebrar dicho matrimonio, sin obstaculizar que alguien más lo hiciese.

\section{Conclusiones}

Los espacios públicos, desde tiempos antiguos, han sido concebidos como lugares de encuentro. En ellos se representa la conjunción de lo privado y lo público, donde los individuos pueden ejercer la tolerancia para lograr la convivencia pacífica. Allí las personas pueden dibujar una línea que separe sus intereses privados de los intereses que comparten como comunidad. En consecuencia, la convivencia se forja a través de la conciliación de los intereses privados, las visiones morales y los beneficios que se pueden alcanzar mediante la práctica de la tolerancia bajo una perspectiva común.

\footnotetext{
${ }^{15}$ Un caso similar fue resuelto en Estados Unidos en el año 1993 (Church of Lukumi Babalu Aye v. City of Hialeah, 1993).
} 
Si bien es cierto que la tolerancia en sentido restringido supone un actuar individual, no es posible abstraer los condicionantes estructurales políticos de las conductas sociales. La tolerancia exige alteridad, interacción y, especialmente, divergencia con el alter, de allí que la construcción de una idea de tolerancia como práctica virtuosa para alcanzar una finalidad común, que no es otra que la convivencia pacífica sostenible, demande una visión reglada bajo el imperio de los principios que orientan la democracia contemporánea de corte liberal.

Todos los casos traídos a colación, ilustran apenas una pequeña dimensión de la complejidad de la sociedad democrática contemporánea, dónde la tolerancia se erige como una herramienta para sobreponernos a los problemas estructurales de la sociedad global. En cada uno de ellos se retrató un conflicto referido a derechos fundamentales ocasionado por las prácticas minoritarias en sociedades con un marco democrático jurídico de corte liberal. Ya sea que se trate del uso de prendas de vestir, la práctica de rituales religiosos, la materialización de rituales atinentes a comunidades de sentido o el desenvolvimiento de la personalidad sobre la base de la propia identidad sexual, cada caso ha supuesto la colisión de derechos fundamentales frente a posiciones de mayorías o grupos de poder.

De igual forma, aun cuando algunos de los casos someramente referidos no comportan una conducta exteriorizada en los espacios públicos compartidos, como si ocurre con las prendas de vestir o las demostraciones afectivas de parejas del mismo sexo, las demás conductas no dejan de tener una relevancia en otro tipo de espacios como los centros sanitarios y lo referente a la salud pública. Dado que la tolerancia como práctica supone compartir espacios y experiencias, la misma se erige como un imperativo ciudadano que quiere evitar que la diversidad cultural sea un obstáculo para la convivencia y la integración. Aunque se aprenda el idioma mayoritario, las costumbres y la historia, "integrarse en la nación [liberal] no requiere abandonar el apellido, la religión, las costumbres o las prácticas recreativas, etcétera" (Kymlicka, 2006, p. 55).

Es precisamente la confluencia de múltiples manifestaciones individuales, lo que ocasiona que en los espacios públicos se requieran restricciones, distintas de la amplitud que se da al ámbito privado, pues la tolerancia sólo es requerida cuando las esferas privadas convergen (Kymlicka, 2006). Por ello, en la sociedad democrática la tolerancia requiere de parámetros orientadores, mientras que la convivencia en los espacios públicos de una sociedad cerrada hace de la tolerancia un acto individual no cimentado en las políticas públicas ni en la conciencia colectiva, inclusive poniendo en riesgo a quienes la practican. Mientras que

En una nación liberal la cultura societaria es abierta y pluralista, adopta cualquier cosa que se considera valiosa de otras culturas, integrándolas en sus propias prácticas, y la transmite a las generaciones siguientes. Es más, esta clase de intercambio cultural se considera algo bueno (Kymlicka, 2006, p. 57). 
Si optamos por la supresión de los conflictos que nos plantea la diversidad, estamos abriendo la puerta a los dos males que advierte Maclntyre (2006): suprimir el ejercicio de derechos de estos individuos o, peor aún, el de la disrupción que se deriva de dicha supresión. La democracia invita a construir una sociedad que permita la integración de la diversidad cultural, pues la alternativa es la imposibilidad de garantizar la convivencia pacífica. Siempre podremos encontrar buenas razones para tolerar, como aquellas que nos ofreció Bobbio (1991): 1. La prudencia política: es mejor la tolerancia que perseguir y reprimir, la intolerancia injustificada no soluciona efectivamente los conflictos; la tolerancia supone una prestación de do ut des, por lo que enaltece la reciprocidad entre quienes la profesan. 2. La convivencia civil: la tolerancia sirve como modo persuasivo frente a la fuerza y la coacción al fiarse de la racionalidad del otro. 3. La tolerancia es un principio moral absoluto: el respeto al otro hace de la tolerancia éticamente obligatoria.

Con arreglo a estas buenas razones, la tolerancia se puede convertir en un imperativo social, cuya razón de ser no radica en aceptar lo que toleramos sino en la aceptación del otro y el respeto que le profesamos por ser también humano, digno y libre. Esa convicción es la que nos lleva a la producción de los beneficios dan forma a la tolerancia como una práctica coherente, compleja, de actividad humana cooperativa, que se arraiga en la sociedad en la medida en que se percibe la utilidad de sus beneficios y propicia una convivencia duradera, estable pero, sobre todo, pacífica.

\section{Referencias}

Aguirre J. (2012). Informe sociográfico de la religión en Venezuela. SIC (745), 212-222.

Alexy, R. (2010). La construcción de los derechos fundamentales. Buenos Aires: Ad-Hoc.

Álvarez de Flores, R. (2007). Evolución histórica de las migraciones en Venezuela. Breve recuento. Aldea Mundo, 11(22), 89-93. Recuperado de http://www.redalyc. org/articulo.oa?id=54302209

Arendt, H. (2007). The promise of politics. Nueva York: Schoken Books.

Arendt, H. (2009). La condición humana. Buenos Aires: Paidós.

Aristóteles (1985). Ética Nicomáquea, ética Eudemia. Madrid: Editorial Gredos.

Arteta, A. (1998). La tolerancia como barbarie. En Cruz, M. (Coord.), Tolerancia o barbarie: occidente ante el reto de la convivencia (pp. 51-76). Barcelona: Biblioteca Económica Gedisa. 
Asamblea General de la Organización de las Naciones Unidas (1948). Declaración Universal de los Derechos Humanos. Recuperado de http://www.un.org/es/ universal-declaration-human-rights/

Australian Medical Association (2017). Female Genital Mutilation, 2017. Recuperado de: https://ama.com.au/position-statement/female-genital-mutilation-2017

Bobbio, N. (1991). El tiempo de los derechos. Madrid: Editorial Sistema.

Bundesministerium der Justiz für Verbraucherschutz (2015). German Civil Code BGB. Recuperado de https://www.gesetze-im-internet.de/englisch_bgb/

Comisión Económica para América Latina y el Caribe (2011). Sistema de indicadores sociodemográficos de poblaciones y pueblos indígenas. Recuperado de: http://celade.cepal.org/redatam/PRYESP/SISPPI/

Church of Lukumi Babalu Aye v. City of Hialeah, 91-948 (11 de junio de 1993). Court of Appeals for the 11th Circuit.

Decreto N² 2015-1475. (2015). Journal Officiel de la République Française, París, Francia, 14 de noviembre de 2015. Recuperado de: https://www.legifrance.gouv. fr/affichTexte.do?cidTexte $=$ JORFTEXT000031473404\&categorieLien $=$ cid

Departamento de Policía de Nueva York (2016). Patrol Guide. Recuperado de: http://www1.nyc.gov/assets/nypd/downloads/pdf/public_information/publicpguide1.pdf

Durham University (2012). District Court of Cologne, Judgment of 7 May 2012 on male circumcision for religious reasons. Recuperado de: https://www.dur.ac.uk/ ilm/news/?itemno=14984

Chumakov, A. (2010). Philosophy of globalization. Moscú: Lomonosov Moscow State University. Recuperado de http://wpf-unesco.org/eng/offpap/top12/alxch.pdf

Department of Work and Pensions (2015). Government overturns turban workplace rule. Recuperado de https://www.gov.uk/government/news/governmentoverturns-turban-workplace-rule

Fetscher, I. (1990). La tolerancia. Barcelona: Gedisa.

Forst, R. (2013). Toleration in conflict, past and present. Nueva York: Cambridge University Press. 
Giner, S. (1998). Verdad, tolerancia y virtud republicana. En Cruz, M. (Coord.), Tolerancia o barbarie: occidente ante el reto de la convivencia (pp. 119-139). Barcelona: Biblioteca Económica Gedisa.

Heyd, D. (1996). Toleration, an elusive virtue. Princeton: Princeton University Press.

Heyd, D. (2008). Is toleration a political virtue? En Williams, M. y Waldron, J. (Eds.). Nomos XLVIII: Toleration and its limits (pp. 171-194). Nueva York y Londres: New York University Press.

Innerarity, C. (2013). El debate sobre el velo islámico en Gran Bretaña: el multiculturalismo liberal y la identidad nacional. Revista de Estudios Políticos (nueva época), (162), 149-174. Recuperado de https://dialnet.unirioja.es/servlet/ articulo?codigo $=4527721$

International Pasta Organisation (2014). The world pasta industry status report 2013. Recuperado de http://www.internationalpasta.org/resources/World\%20 Pasta\%20Industry\%20Survey/IPOstatreport2014low.pdf

King, P. (1998). Toleration. Londres, Portland: Frank Cass Publishers.

Kymlicka, W. (1996). Ciudadanía multicultural. Barcelona: Paidós.

Kymlicka, W. (2004). Estados, naciones y culturas. Córdoba: Almuzara.

Kymlicka, W. (2006). Fronteras territoriales. Madrid: Trotta.

Laborde, C. (2003). Toleration and laïcité. En McKinnon, C. \& Castiglione, D. (Eds.), The culture of toleration in diverse societies, reasonable tolerance (pp. 161178). Manchester: Manchester University Press.

Consejo de Estado Francés (26 de Agosto de 2016). La Ligue des droits de l'homme. Recuperado de: http://www.conseil-etat.fr/Actualites/Communiques/Mesure-dinterdiction-des-tenues-regardees-comme-manifestant-de-maniere-ostensibleune-appartenance-religieuse-lors-de-la-baignade-et-sur-les-plages

Univisión. (29 de diciembre, 2016). La Policía de Nueva York permitirá a sus agentes llevar turbante y barba larga por motivos religiosos. Recuperado de http:// www.univision.com/noticias/policia/la-policia-de-nueva-york-permitira-a-susagentes-Ilevar-turbante-y-barba-larga-por-motivos-religiosos

Journal Officiel de la République Française (17 de marzo de 2004). Ley 2004-228. Recuperado de: https://www.legifrance.gouv.fr/jo_pdf. do?id=JORFTEXT000000417977 
BBC Mundo (15 de agosto de 2016). Lo que piensan las musulmanas del mundo sobre la prohibición de "burkinis" en las playas de Cannes, Francia. Recuperado de http://www.bbc.com/mundo/noticias-37084542

López Calera, N. (1992). Derecho y tolerancia. Jueces para la democracia, (1617), 3-8.

Maclntyre, A. (2006). Ethics and politics, selected essays. Cambridge: Cambridge University Press.

Maclntyre, A. (2013). Tras la virtud. Barcelona: Editorial Crítica.

Marcuse, H. (1965). Repressive tolerance. En Wolff, R.; Moore, B. \& Marcuse, H. A critique of pure tolerance (pp. 81-118). Boston: Beacon Press.

McKinnon, C. (2006). Toleration, a critical introduction. Londres y Nueva York: Routledge.

El mundo (12 de agosto de 2016). La alcaldía de Cannes prohíbe el 'burkini' en sus playas. Recuperado de http://www.elmundo.es/internacional/2016/08/12/57a e09b1ca4741683c8b45a8.html

Mill, J. (1970). Sobre la libertad. Madrid: Alianza Editorial.

Mill, J. (1984). El utilitarismo. Madrid: Alianza Editorial.

Murphy A. (1997). Tolerance, toleration and the liberal tradition. Polity, 29(4), 593-623.

Corte Suprema de Justicia de EE.UU (26 de junio de 2015). Departamento de Salud de Ohio y otros, 14-556.

Ordenanza modificatoria sobre tenencia, control, registro, comercialización y protección a la fauna (16 de junio de 2006). Gaceta Municipal del Municipio Bolivariano Libertador N²765-1, Caracas, Venezuela.

Organización Mundial de la Salud (2012). Mutilación genital femenina. Recuperado de http://www.who.int/mediacentre/factsheets/fs241/es/

Popper, K. (1995). La responsabilidad de vivir, escritos sobre política, historia y conocimiento. Barcelona: Paidós.

Popper, K. (2006). La sociedad abierta y sus enemigos. Barcelona: Paidós. 
El Mundo (3 de septiembre de 2016). Prisión para la funcionaria estadounidense que se negó a dar licencias a matrimonios gays. Recuperado de http://www. elmundo.es/america/2015/09/03/55e88e8a268e3e78308b4596.html

Rawls, J. (2001). El derecho de gentes y "una revisión de la idea de razón pública". Barcelona: Paidós

Scanlon, T. M. (2003). The difficulty of toleration, essays in political philosophy. Cambridge: Cambridge University Press.

Thiebaut, C. (2010). Tolerancia y hospitalidad. Una reflexión moral ante la inmigración. ARBOR. Ciencia, pensamiento y cultura, 186(744), 543-554.

Troconis de V. E. (1986). El proceso de la inmigración en Venezuela. Caracas: Academia Nacional de la Historia.

Universidad de Los Andes Venezuela (1995). Población de Venezuela desde el año 1900 hasta el año 1995. Recuperado de: http://iies.faces.ula.ve/censo/pobla vene.htm

Uribe, P. (2016). Evolución del concepto de tolerancia con miras a una cultura de la tolerancia sustentada. Tesis doctoral no publicada. Universidad del País Vasco, Donostia-San Sebastián, Guipúzcoa, España: n/a.

Uribe, P. (2016b). La ponderación de los derechos fundamentales de Robert Alexy y su utilidad para la solución de los problemas de tolerancia. Revista Tachirense de Derecho, (27), 95-112.

Walzer, M. (1998). Tratado sobre la tolerancia. Barcelona y Buenos Aires: Paidós.

Yurdakul, G. (2016). Jews, Muslims and the ritual male circumcision debate: religious diversity and social inclusion in Germany. Social Inclussion, 4(2), 77-86. Recuperado de http://www.cogitatiopress.com/socialinclusion/article/view/494 